\title{
De voorgeschiedenis van het Wilhelmietenklooster te Brugge
}

De XIde en XIIde eeuw kenmerken zich door de stichtingen van vele en velerlei nieuwe Ordens. De abdijen van Benediktijnen, de monasterieën van reguliere kannuniken, de huizen van de Joannieterorde, Tempelrisders en vooral van de bedelorden, vonden in de Zuid-Nederlanden een grote bijval, de vrouwenkloosters rezen als paddestoelen uit de grond (1). Sedert de Evangelisatie in de Nederlanden ontstonden ook vanaf de VIIde, maar vooral in de XIde en de XIIde eeuw heel wat ermitages, door eenzame kluizenaars gebouwd, die midden de woeste onbebouwde landerijen of buiten de steden hun kluizen optrokken, in de nabijheid van een bron met drinkbaar water; zij begaven zich aan gebed en meditatie, verscholen voor de gemeenschap in een primitieve van hout en riet gebouwde hut (2). De kluizenaars liepen blootsvoets, droegen een grove pij met schoudermantel en kap, en lieten hun baard en hoofdhaar groeien. Het waren gestalten van boete en gebed. De Wilhelmieten, in de "Stal van Rhodes" bij Siëna gesticht door de $\mathrm{H}$. Wilhem van Malaval, een Frans ridder, door Albertus en Raynaldus later georganiseerd tot een kluizenaarsorde, droegen in het begin van de stichting een bruin habijt van grove stof, liepen blootsvoets en hadden veel vasten- en boetedagen; hun leven was zo streng doorgevoerd, dat het bijna onmenselijk werd.

(1) E. de Moreau, Kerk en geestelijk leven van het Concordaat van Worms tot het einde van de dertiende eeuw, in Algemene Geschiedenis der Nederlanden, Utrecht, 1950, dl. II, bl. 509.

(2) G. Boulmont, Ermitages, Brussel, 1892, bl. 92, 93; G. Boulmont, Nos anciens Ermitages, Brussel, 1903, bl. 95 en vlg. 
Paus Gregorius IX verleende hen de Regel van St. Benediktus, schonk hen het witte habijt met zwart schapulier, het missaal en het brevier van de Benediktijnen in 1228. Innocentius IV gaf hen in 1248 de titel van "Eremijten van St. Wilhelm" en Clemens III schonk hen in 1266 de bulle van autonomie met het recht op privilegies, bezittingen en tienden (3). Eerst maar bij het concilie van Bazel in 1435, toen de kluizenaars zich over bijna gans Europa hadden verspreid, werd de Orde ingedeeld in drie grote provincies, met een provinciaal aan het hoofd, en een prior aan elk huis.

Vóór die indeling waren de Wilhelmieten reeds over de Nederlanden talrijk gevestigd in een menigte van Ermitages. Bazeldonk werd gesticht in 1245, door een zekere edelman Winand Bazel, die buiten 's Hertogenbosch op zijn uitgestrekt leen, dat zijn naam zal dragen, een kluis stichtte, die uitgroeide tot een klooster (4); er moeten zich veel novicen hebben aangeboden om het strenge boeteleven te aanvaarden, want dit huis wordt de bakermat van de andere conventen, die in snel tempo vertakten en zich vermenigvuldigen.

Het eerste huis echter was dat van Biervliet in de woestine, gesticht in 1249. Dan volgden : Bernardfagne (Ferrières) in 1249, Mariagaarde in 1249, Groot- en Klein Duren in 1255, Walincourt bij Kamerijk in 1255, Nieuwland bij Flienes in 1256, Parijs, het huis Montrouge, buiten de stad in 1256, Aalstbing 1260, Vloesberg bij Lessen in 1263, Nijvel in 1267, Huibergen bij Bergen-op-Zoom in 1278, 's Grevenbroek bij Keulen in 1280, Parijs, les Blanc-manteaux in 1298 (5), zodat op

(3) Petrus Silvius, Vita S. Guilielmi Eremitae, Brussel, 1626. app. bl. 4.

(4) Geschiedenis van het Wilhelmietenklooster te Huybergen, Bergen-op-Zoom, 1907, bl. 10 en vlg.

(5) P. Hélyot, Histoire les Ordres religieux, Parijs, 1863, dl. II, bl. 438 . 
het einde van de XIIIde eeuw, de Wilhelmieten fel verspreid waren in onze streken, doch meestal buiten de omheiningen van de steden of midden de landvlakten, langs de grote banen om er een gasthuis open te houden voor "passante pelgrims" of voor vermoeide en verdwaalde reizigers, een apostolaatsvorm die ze maar aangenomen hebben sedert het einde van de XIIIde eeuw onder invloed van de nieuwe Regel van St. Benediktus, die de gastvrijheid en het ontvangen van Christus in de vermoeide reizigers voorschreef (6), „De hospitibus suscipiendis". Deze kenmerkende trek voor hun latere kloosters vinden we niet vermeld bij de Biervlietermonniken waarover het hier gaat; vermoedelijk hebben zij eerst de Regel van St. Augustinus gevolgd, waarover er tussen de verscheidene huizen heel wat innerlijke twisten ontstonden, daar ze zich innig door éénzelfde doel met de Augustijnereremijten verbonden wisten.

Heel eigenaardig is dan ook de benaming die in de meeste en oudste schenkingsakten voorkomt ten voordele van het Biervlieterconvent: „, fratres Eremitae de Wastina Beatae Mariae".

Het was pater Hugo van Antwerpen die door de overste van Bazeldonk werd aangeduid om te Biervliet in de woestine te gaan stichten in 1245 (7), daarin bevestigd door zijn provinciaal frater Joannes. Wat tot die stichting aanleiding heeft gegeven is ons niet bekend, maar wij vermoeden dat, zoals het met menigeen van hun stichtingen ging, er reeds kluizenaars moeten gewoond hebben midden die wildernis, doch die vrij leefden, aan geen Regel gebonden waren en mogelijk verlangden zich bij een geordende eremijtenorde aan te sluiten, geholpen door de grote landeigenaars, die er een zegen

(6) J. Baudot, Dict. Connaissances religieuses, Parijs, 1926, dl. III, bl. 658; B. Wuyts, Regula Sti Benedicti, Westmalle, 1881, cap. L. III, bl. 113.

(7) Bollandisten, Acta SS., Antwerpen, 1658, 10 febr., bl. 480. 
in zagen bidders op hun grondgebied te mogen huisvesten.

Zo zijn de Wilhelmieten gaan stichten te Bernardfagne in 1249, op het landgoed van een zekere Adelard Roeneus, die een uitgebreide kluis ter ere van O.L. Vrouw gebouwd had op een oudere kluis in 1188 door een priester Wericus opgetrokken en bewoond (8); deze kluizenaars sloten aan met de Wilhelmieten en dat was de oorsprong van het klooster.

De Biervlietermonniken zullen later in 1276 zelf uitzwermen naar Nijvel, doch ze zullen zich vestigen op reeds door kluizenaars bewoond gebied: want er was reeds in oude tijden een ermitage gesticht met een eigen Regel, doch die werd door paus Gregorius X (1271-1276) niet goedgekeurd en de kluis werd afgeschaft; het is dàn dat deze eenzaten zullen aansluiten om te kunnen blijven bestaan en de Regel van de Wilhelmieten zullen aannemen, met wie ze verbroederen; zo ontstond het klooster te Nijvel (9). In het land van Waas, in de VierAmbachten en rond Aardenburg hadden kluizenaars zich genesteld, onder meer "in de woestine", nu de Noordpolder genaamd, te Salegem (Vrasene) waar in 1123 de kluis werd gebouwd, te Coesvoorde in 1136, te Hulsterlo en te Baudelo in 1189, te St.-Jan-in-Eremo dicht bij Watervliet-Biervliet gelegen (10); in de omgeving waren er in Zeeuws-Vlaanderen de kluizenaars van Elmare ten zuiden van IJzendijke, op ongeveer $10 \mathrm{~km}$ van Biervliet; ze worden vernoemd in Reynaert de Vos,

(8) Bart. Fiesen, Historia Ecclesiae Leodiensis, Doornik, 1642, bl. 387 .

(9) A. Tarlier-A. Wauters, Géographie et histoire des communes Belges, Ville de Nivelles, Brussel, 1862, bl. 147; J. H. Gauze, Les Guillielmites, in Spectator (van Nijvel) jan. 1958; G.C.A. Juten, De Orde van de H. Guilielmus in Noord- en Zuid-Nederland, in Analectes pour servir à l'hist. ecclésiastique de la Belgique, dl. 32, 1906, bl. 44-67.

(10) K. Vossen, Het Ontstaan der parochies in Waas in Annalen van Waas, dl. 53, 1943, bl. 116. 
v. 372-74, waarin Reyneke zich vertoont als monnikkluizenaar, gekleed met de monnikspij, geschoren kruin en met de pelgrimsstaf in de hand, terwijl hij onder de mantel een haren boetekleed draagt. Dit kluizenaarsconvent werd gesticht in 1144; de meeste van die genoemde kloosters lagen „up de moer in die woestine " v. 26661 (11).

In Zeeuws-Vlaanderen waren het de grote abdijen, St. Baafs en St. Pieters van Gent, Ter Duinen, Ter Doest en Cambron, die er de grote landeigenaars waren, de bezitters van uitgestrekte tiendelanden; zij waren ook de grote indijkers van de moerassen en welen, de veroveraars van het vruchtbare land op de zeevloed veroverd (12). Het is dus heel goed mogelijk dat, door het toedoen van deze groten en op aanbeveling van gravin Margareta van Vlaanderen en Henegouwen, de Wilhelmieten een ermitage, die uitgestorven was of geordend verlangde te leven met vaste Regel, hebben overgenomen en er de stichting naar eigen geest en leest hebben uitgebouwd.

Het klooster van de Wilhelmieten is gemakkelijk te situeren : het lag in het gebied dat tot het Ambacht van Bouchoute behoorde, doch rechtsgebied van Watervliet. Het klooster vormde de grens tussen de Nieuwe Keure van Watervliet en de Keure van de Vier-Ambachten, de grens tussen Kroon- en Rijks-Vlaanderen (13). De prior

(11) J. Teirlinck, De Toponymie van den Reinaert, Gent, 19101912, bl. 49-50.

(12) Dr. M.K.E. Gottschalk, Historische Geografie van Westelijk Zeeuws-Vlaanderen, Assen, 1958, dl. I, bl. 837.

(13) Ibidem. - Bij J. Walters, De eerste geloofspredikers op het grondgebied van het huidige bisdom Gent, Gent, 1946, lezen we het volgende : „Omstreeks 1243 kwam Walter van Marvis, bisschop van Doornik, de grenzen vaststellen van Bassevelde, Lembeke, Oosteekloo en Watervliet. Dat lokte protest uit vanwege de Utrechtse Kerkvoogd. Naar alle schijn deed hij beroep op paus Innocentius IV, want in februari 1245, benoemde de H. Stoel drie scheidsrechters om het geschil bij te leggen. Zoveel haken en ogen kwamen nochtans aan die zaak, dat enkel in 1264, de toenmalige 
tekende zelf met die grensbepaling de akten : „prior fratrum Willeminorum de loco beatae Mariae de Moro juxta Pietem", "Sente Marien clooster van Wastine dat hier voormaels ghestaen heeft in de prochie van Bouchaute aen de Piete" (1278).

Het schijnt dat Margareta van Vlaanderen een uitgesproken genegenheid koesterde voor de Wilhelmieten van Biervliet, die ze zo rijk met schenkingen had bedeeld, zodat de zoon Gwijde van Dampierre in later door hem bevestigde akten daar op zinspeelt: "ego Guido, comes Flandriae collationem et eleemosynam a karissima Domina et Matre mea praedicta, dictis Fratribus, prout superius est expressum, laudo et approbo et gratas habeo" (14).

In het Rijksarchief te Gent (15) worden ongeschonden de oorspronkelijke schenkingsakten op perkament, met hun originele zegels versierd, bewaard waarvan we de korte inhoud hier aangeven :

„De 12e maart 1255 schenkt gravin Margareta aan de Wilhelmieten-eremijten, één bunder land, gelegen in de Jorismoer (Morum Georgii) tot zielelafenis van haar overleden bloedverwanten en tot eigen heil. Het stuk is voorzien van haar groot zegel in bruine was, de gravin in hofkledij voorstellend en als tegenzegel haar wapenschild (16).

De 10 e april 1258 verleent zij aan de prior en de ere-

Kerkvoogden van Doornik en Utrecht er in toestemden de uitspraak te aanvaarden van twee arbiters door gravin Margareta aangesteld. Deze verklaarden dat Oostleekloo en zijn abdij, Kaprijke en Lembeke behoorden bij het bisdom Doornik en dat het klooster van de Wilhelmieten afhing van Utrecht. Naar een getuigenis van 1280 vormde de straat vóór de kloosterpoort de scheiding der Vier-Ambachten met de nieuwe Keure van Watervliet : het klooster behoorde dus bij het ambacht Bouckhoute".

(14) Mireaus, Opera Diplomatica, Brussel, 1882, dl. III, bl. 122.

(15) Fonds Bethlehemklooster-Deinze (1232-1469), Doos N ${ }^{\circ} 3-4$. $\mathrm{Al}$ deze stukken zijn later in de XVde eeuw overgeschreven in het cartularium van het St. Marganetaklooster.

(16) Ibid. Map 1. 
mijten van St. Wilhelm een cijns van 8 deniers Vlaamse munt, om jaarlijks het overlijden van haar echtgenoot te celebreren, "plechtig in de kerk van het convent". Wat dus bewijst dat de kluizenaars zich een ruim gebouw hebben opgetrokken dat als klooster dienst deed, met daarnaast een ruime kapel, waar zij de goddelijke getijden, naar St. Benediktus Regel, zongen en de openbare diensten verrichtten.

Uit een stichtingsakte van het convent te Peene in 1261, vernemen we dat de Wilhelmieten gewoonlijk met zes monniken een huis vormden, vier paters en twee lekebroeders, "secundum consuetudinem ordinis vestri " (17), alhoewel dit getal mocht toenemen, in het vooruitzicht later uit te zwermen. De 12de februari 1262 schenkt de gravin „Fratribus Heremitis Ordinis Sti Wilhelmi" 6 bunder land gelegen te Benthil bij Biselvere en twee maand later in april verruimt ze die gift tot 20 bunder woestinegrond (18). De 10e februari 1263 doet ze een tweede schenking van 80 bunder woeste grond gelegen aan de Paradijsstraat, waarop de monniken de tienden mogen heffen, alles in aalmoes tot meerdere eer van God en tot lafenis van de zielen harer bloedverwanten (19).

In oktober 1272 geeft ze nog 10 bunder moergrond, gelegen bij Waterschot en voegt er in 1275 nog 41 gemeten land bij met de tienden gelegen te Bouchoute (20). In dit zelfde jaar verkrijgen de eremijten nog een rente van 29 schelling groot op landen te Biervliet, van Hugo gezeid de Zoete van Biervliet (21).

Eerst in 1278 verkregen de monniken 54 bunder land waarop ze belastingen te betalen hadden, 56 schellingen

(17) Mireaus, o.c., bl. 121.

(18) R.A.G., o.c., Map. 2.

(19) Ibid. Map 3 en 4.

(20) Ibid. Map 5.

(21) Ibid. Map 6. 
per jaar, doch kort daarop, de 7 de oogst reeds van het zelfde jaar werd hen door de gravin kwijtschelding verleend en werd de belasting omgezet in "een pitancie" van wijn, die gegeven moest worden voor de helft op het anniversarium van Margareta's zuster dat in de kerk moest gecelebreerd worden, en voor de tweede helft op de dag na St. Jans-Onthoofding. Tevens verkregen de Wilhelmieten verlof om 41 gemeten land bij te kopen in de Alvericspolder. Dan volgen in de komende jaren een hele serie schenkingen van partikuliere aard, kopingen en verkopingen, pachtingen en verpachtingen, bijna allen in de omgeving van het convent, in de St.-Jorispolder, in de St.-Salvatorspolder en Sinte-Clemenspolder (22).

De eigendommen van de Wilhelmieten kunnen zo worden samengevat: 50 gemeten moergrond in DirkCleiland; 1 bunder moergrond om er turf te steken voor eigen gebruik en voor de handel; 20 bunder in de wastina van O.L. Vrouw; 80 bunder te Watervliet in de Lestraat en de Paradijsstraat; 80 bunder tiendenlanden; 2 bunder om er een watergang te graven; 10 bunder met een jaarcijns aan 9 penning Vlaams; 41 gemeten in de Alvericspolder; $241 / 2$ gemeten turfgrond in de moeren.

In 1293 verkregen ze dan van Gwijde van Dampiere, verlof om langs de wegen en de landerijen wilgebomen te planten en zelfs boomgaarden aan te leggen , juxta novem plantationem Willeminorium" (23).

In al deze akten van de gravin uitgegaan, worden er geen paters genoemd, steeds is het ", prior et fratres eremitae", zodat ons buiten de stichter Hugo van Antwerpen, de eerste monniken niet gekend zijn; een zekere broeder Ghijsbrecht, die in de Beatrijssproke wordt vernoemd, moet tot deze communiteit hebben be-

(22) Ibid. Map 7 en 8.

(23) Gottschalk, o.c. 
hoord (24); dan zijn ons bekend : 1265 - frater Hendrik (25); 1267 - fr. Julianus en Walter, die gaan stichten naar Nijvel; 1289 - fr. Jacoppe, prior van den Godtshuyse van Willeminen; 1292 - fr. Janne van den Elmare; 1332 - Broeder Pieter Doelemont, prior van de Willemijnen; 1357 - Broeder Arnoud den Coorenbittere den Willemijn; 1357 - Broeder Willem Pharante prior van den Willemijnder Wastine; 1368 - Broer Clais Bortoene; 1342 Broeder Wouter Jooszoon Woutre Lambrechts zoens van den Willeminen clooster; 1367 - Broeder Willems Scule van Ryssele; 1390 - Broeder Willem van Praet en Broeder Jan den Backere syn neve; 1395 - Broeder Michiel van den Willeminen; 1392 - Broeder Wouter van Wevelswale.

Het was in 1276 dat de Biervlietermonniken gingen stichten te Nijvel, na een akkoord te hebben gemaakt met de generaal die te Grosseto in Italië verblijf hield: „Frère Guillaume, prieur général de l'ordre des Guillielmites donne son approbation aux lettres de l'official de la Morinie du 23 décembre de l'année précédante, datum apud Heremit. Sti Guillielmi Grossetanensi anno 1275 " (26). Uit een brief van frater Joannes, prior generaal in 1276 , is uit te maken dat het klooster van St. Katerina gesticht werd door een poorter van de stad Nijvel, Eustache de Roeulx, sire de Trasignies et de Trieth, in een buitenwijk van de stad. Reeds vóór dit klooster werd gesticht, was er in de Chaudesrue een niet erkende ermitage met eigen levensregel, door Gregorius $\mathrm{X}$ ontbonden; de Wilhelmieten hebben eerst dit huis willen

(24) Alb. Thijm, Legenden en Fantaziën, Amsterdam, 1859; J. A. Jonckbloet, Beatrijs, Eene sproke uit de XIIIde eeuw, 's Gravenhage, 1841; P. Stracke, in Leuvesse Bijdragen, 1927, bl. 58; P. Janssens, Een Cisterciënser van Baudelo dichter van de Beatrïssproke?, in Ons Geestelijk Erf, 1960, bl. 186-196.

(25) R. A. Gent, o.c., Cartularium, zie jaartallen.

(26) A. Wauters, Table Chronologique des chartes et diplomes imprimés, Brussel, 1877, dl. V, bl. 334. 
overnemen : maar er kwam zoveel tegenstand vanwege het kapittel en de alvermogende dame van Nijvel, de abdis der nobele kannunikessen, dat eindelijk na beraadslagen beide partijen tot een overeenkomst geraakten. De Wilhelmieten zouden buiten de stad bouwen, aan de rivier de Thines, waar ze een hospitium zouden openen voor passante pelgrims (27).

Ondertussen moest het Biervlieterconvent heel wat leden hebben kunnen aanwinnen om de leemten bij dit uitzwermen te kunnen aanvullen. Te meer dat er in deze streken van moerassen, kreken, lage gronden, veel werk was om het gewonnen land in te dijken, de dijken regelmatig te versterken en de gedreineerde gronden te bemesten en te bezaaien. We weten niet van een groot opzet, maar zeker is het dat ze, naar het voorbeeld der grote abdijen die in de omgeving lagen, hebben uitgezien naar een rijkst mogelijke opbrengst van hun kultuurlanden. Ze hebben zeker grote verwachtingen gekoesterd en hadden er zelf een kerk gebouwd met de gedachte dat het volk zich in de omgeving zou komen vestigen, als pachters, indijkers met hun polderwerklieden, die dan hun kerk zouden ondersteunen en begiftigen.

Toponiemen, nu nog in zwang, getuigen van hun noeste arbeid om die woeste landen vruchtbaar te maken : "de Willemijnbos" te Bouchout, "de Willemijngeule", de "prioerenwech" enz. (28).

Hun eerste nederzetting was reeds een mislukking, want in 1304 verkregen ze van de abt van St. Baafs te Gent, Walter van Erdenborch (1295-1305), 20 bunder heidegrond om er ,een convent te bouwen " te Hanne-

(27) Tarliers, o.c., bl. 7 .

(28) F. De Potter, Geschied. der gemeenten van Oostvlaanderen, Gent, 1872, Bouchout, bl. 11, Watervliet bl. 58, 67, Assenede bl. 223. 
kinswerve (29), omdat de lagere drassige gronden bij overstromingen geen voldoende waarborg boden. Hun eerste voorlopig klooster was vermoedelijk uit hout opgetrokken op stenen fondamenten, het tweede was uit baksteen gebouwd.

Op 16 november 1377 „, is sulk een tempeest der winden opgeresen, dat men tot nog toe noyt sulckx gelijk en hadde gesien ofte gehoort. De opswellende Ocean zijn geweldige baeren worpende in het gat van Biervliet, heeft aldaer een groote openinge gemaeckt en aldus synen onvullycken schoot vergroot met 17 dorpen; alwaer menschen en beesten verdroncken, huysen, stallen en scheuren op de waetren gevaert wierden en niet als baeren en wierden gesien. De schaede en is hier niet berekelijk, dewelcke door de onachtsaemheyt der sluys-meesters was ingevoert; gemerkt de sy seer nauwkeurig waeren om het inghestelt dijckgeldt op te haelen en uyt te persen, hetwelkt sy meer besteden tot onnuttighe gebouwen en koopingen als tot het noodig onderhouden van dijcken en sluysen. De overwaterde plaetsen waeren dese : geheel Ysendijcke, S. Nicolaus, Elmetre, Roeselaere, Ooymanskerke, Piete, St. Catherine ten Hamere, S. Jan in de Wildernis (in Eremo), een deel van Schoonendijcke, Hugenfliet, een deel van St. Marie van Biervliet Bouchaute, t' Clooster der Guillielmijten, enz." (30).

Hier wordt dus het klooster niet meer vernoemd "aan de Piete ", maar verder gelegen in de richting van Watervliet, al hebben ze hun landerijen aan de grensstreek wel bewaard. De monniken hebben een hoger gelegen zandvlakte gekozen, waar ze bij grote stormen ook niet veilig waren.

(29) A. Van Lokeren, Histoire de l'abbaye de St. Bavon, Gent, 1855, dl. II, Chartês et documents, bl. 50 .

(30) Nicolas Despars, Chronijcken van Vlaenderen, Brugge, ed J. De Jonghe, 1837, dl. I, bl. 37. 
Het is een feit dat alle mogelijke middelen werden aangewend om door nieuwe dijken het verdronken land zoveel mogelijk terug te winnen op de vloed, maar ze zijn er niet helemaal ingelukt, al hadden ze er al hun krachten en kapitalen voor ingezet.

Een tweede ramp komt definitief hun eigendommen teisteren. "Omtrent de feestdag van S. Elisabeth, den 25 November 1404, heeft men nooyt groter overvloet van water in Vlaenderen gesien, den welken drij mijlen verr' onse landen aen den zee-strandt heeft overspoelt, veel menschen en beesten versmagt, gebouwen, scheuren en stallen afgeworpen, besonderlijk in de Vier-Ambachten, tot Sluys, Damme, Ardenburg, Oostburg, Biervliet, Hugenfliet, Wulpen, Cadsant en Bouchoute, welke Plaetsen de grootste schaede hebben geleden, waer veel ingedijkte landen sijn vergaen..." (31).

Weer hadden ze getracht hun land te herwinnen door het aanleggen van nieuwe dijken, , doch dat sy gheensins vermeughen 'tselve land bedijken en recupereren" (32). 88 jaar hadden ze gezwoegd, zonder enig resultaat. Zoveel zwoegen en hard labeur hadden die landerijen gevergd en ze hadden niets opgeleverd. De kloostergemeente was door deze twee rampen zo verarmd dat ze niet meer bij machte was haar land terug te winnen.

Toen hebben de monniken uitgezien naar een nieuwe woonst, waar ze veilig hun religieus ideaal konden verwezenlijken, vredig en rustig zoals hun medebroeders, uit andere conventen, buiten de gevaarlijke vloedzone; ze kozen Brugge. In 1430 zijn de eerste monniken toegekomen om er aan de Gentpoort, op een aangeworven terrein met de bouw te beginnen van het klooster, St. Antoniusdal genaamd; in 1433 hadden ze reeds gebouwd, vermits de stad Brugge hun in dit jaar een toelage voor

(31) Ibidem, dl. II, bl. 133.

(32) R.A. Gent, Cartularium, o.c. 
de bevloering van het convent had uitgekeerd (33); in 1434 worden ze reeds in een stadsrekening aangetekend gevonden : " de strate te Willeminen die men heet de dreve".

Eenmaal hier gevestigd, hebben ze kapitalen nodig voor de bouw van hun kerk en hospitium en ze zien uit naar de verkoop van hun landerijen in de Noordpolder.

Zo verkopen ze aan een zekere Antoon de Baenst van Bouchoute, 64 gemeten land in 1465, en 300 gemeten aan St. Margrietesconvent te Deinze, ook Bethlehem genaamd, mits een eeuwigdurende rente te betalen van 20 deniers Vlaams per gemet met ingang van 1467. De paters van Bethlehem mochten, na het droogleggen van de geteisterde landen, de gronden verpachten in naam van de Wilhelmieten, kwitanties afleveren, en procederen. Dat was alles wat er van hun vroegre bezittingen overschoot (34). Tekenden de akte van verkoping; ,prior Geeraert Pottere, paters Geeraert de Meyere, Bernard Naghelmakere, Arnold Janszone, conventuelen ".

Hun kerk werd geconsacreerd de 16 oogst 1478 door de bisschop van Doornik, in tegenwoordigheid van Maximiliaan en zijn gevolg (35). Zo werden de Wilhelmieten ingeburgerd te Brugge, waar ze een belangrijke invloed zullen uitoefenen door hun latijnse school (36), doch die gefnuikt wordt bij de Hervormingsonlusten. Bij hun terugkeer naar de stad, maken ze zoals al hun huizen een

(33) A. Duclos, Bruges, histoire et souvenirs, Brugge 1910, bl. 569. - G.C.A. Juten, Het klooster der Guilielmieten te Biervliet en Brugge, in Annales de la Société d'Emulation, LVII (1907). bl. 63-73.

(34) F. De Potter o.c. Watervliet, bl. 58-69. geeft heel de verkoopakte aan. Vgl. A. Vanden Abeele, Geschiedenis der stad Deinze, Gent, 1865, bl. 175.

(35) A. Duclos, De Wilhelmieten te Brugge, in Rond den Heerd. dl. II (1866), bl. 85.; dl. VII (1872), bl. 102. Zie ook : M. English, Een relikwie van $S$. Willem te Brugge (1701), in Biekorf 1938, bl. 189-191.

(36) A.C. De Schrevel, Histoire du Séminaire de Bruges, Bragge, 1895, dl. I, bl. 56. 
zware strijd door, daar ze door het aangaan van leningen, om hun huizen en kerk te herstellen, de schulden nooit te boven komen en zich zodanig bezwaren dat ze materieel en ook moreel ten ondergaan.

Hun religieus leven was niet altijd voorbeeldig; zoals Mgr. Triest op het concilie van de Belgische bisschoppen moest klagen over de wereldse geest der Wilhelmieten van Beveren-Waas, en Mgr. Zoesius van 's Hertogenbosch over het Wilhelmietenklooster van zijn bisschopsstad over het gebrek aan regeltucht, zo moest ook Mgr. van Susteren later heel wat misbruiken in het St. Antoniusdalklooster constateren, zodat de bisschoppen overeenkwamen aan de paus (37) voor te stellen de Wilhelmieten hun exemptie te ontnemen en ze onder de jurisdictie van de bisschoppen te stellen, ofwel de afschaffing der orde aan te vragen.

Te Brugge restten er amper nog vier paters in 1764 en op het provincaal kapittel van de Wilhelmieten gehouden te Aalst, werd door provinciaal Judocus Canis, op aandringen van Mgr. Van Susteren besloten de Brugse paters aan te sluiten bij het klooster van Nijvel, dat personeel te kort had.

Op 18 december 1764 werden ze werkelijk bij het convent van Nijvel ingelijfd. De prior van Nijvel verkocht de Brugse gebouwen in 1766, terwijl de kerk der Wilhelmieten een tijdlang nog dienst bleef doen als parochiekerk (38), ter vervanging van de geteisterde St. Catherinekerk.

De Wilhelmieten zijn verdwenen bij gebrek aan eenheid in de Orde, daar ze door onderlinge twisten steeds verdeeld waren; hun huizen stonden onafhankelijk van mekaar met eigen stabilis loci voor de leden; midden dat

(37) Mgr. de Ram, Synodicum Belgicum, Mechelen, 1828, dl. I, bl. 464,471 .

(38) Rond den Heerd, dl. VII (1878), bl. 85 en 100. 
kleine getal paters was de geschikte man met de nodige talenten om overste te zijn niet altijd te vinden; onderkomen uit armoede die hen buiten huis dreef voor hun onderhoud, verloren ze door hun uithuizigheid, hun geest en regeltucht; ze werden door Jozef II in 1784 afgeschaft en gelaïciseerd, hun goederen tot staatsdomein verklaard en verkocht.

Heel wat Orden vonden de kracht om zich weder op te richten, en op het oude puin een nieuw religieus leven herop te bouwen. De Wilhelmieten maken op die regel een bijna enige uitzondering.

P. JANSSENS, C.SS.R. 